\title{
ANALGESIA IN OBSTETRICS
}

\author{
By P. J. Helljweli, M.B., Сн.B., D.A., \\ and \\ A. Michael Hutton, M.R.C.S., L.R.C.P., D.A. \\ Department of Anaesthetics, Guy's Hospital
}

During the past few years the problem of the control of pain in obstetrics has received much attention from obstetricians, anaesthetists and general practitioners, and the methods employed have undergone a profound change. More elaborate methods have been made possible by the growing tendency for the mother to have her confinement in an institution rather than at home and it is felt that as more beds become available this will occur more and more frequently. In spite of this, today, the majority of confinements still take place at home where the mother is attended by a domiciliary midwife acting alone ; and for these patients also new methods have become available.

It is now no longer considered satisfactory merely to give analgesic drugs when the labour pains are severe, as although there are now innumerable drugs available for this purpose most authorities realize that one of the most important factors contributing to a pain free labour lies in the mental attitude with which the mother approaches her confinement. This correct mental approach can only be obtained by careful education in the antenatal period and therefore the modern technique of treatment falls into two main divisions :-

(A) Antenatal instruction and explanation.

(B) Methods employed during the labour itself.

These methods can be grouped as follows :-

(a) Drug therapy by the oral, hypodermic, intravenous or rectal routes.

(b) Inhalational agents employing an apparatus.

(c) Local or regional analgesia.

Normally a combination of two of these methods is used.

\section{Antenatal Instruction}

From the earliest days of the patient's antenatal supervision it is essential for the obstetrician or practitioner to explain to her the normal processes of pregnancy and labour. Under no circumstances must the mother be allowed to commence her labour in a state of terror arising from the fear of the unknown, or from the exaggerated stories of well-meaning but unwise friends and relations.
The patient must be confident that she will receive help from her attendants whenever it is required and know that she will not suffer the agonies which a less fortunate woman tends to expect. Clinical experience has shown that better results may be expected from a willing and co-operative patient whatever type of analgesia is used, and towards the end of her antenatal period a decision should be made on broad lines as to what method of analgesia will be employed in her case. If any inhalational apparatus is to be used, at one of her final antenatal visits she should be shown the apparatus and given instruction in its use. In the case of gas and air Minnitt ${ }^{1}$ maintains that the patient must realize that the analgesic is self administered and that she will not become unconscious.

In stressing the importance of this, Minnitt further considers that in his opinion one of the main causes of failure of gas and air analgesia from a self-administered machine is the inadequate education of the patient in its use. These remarks apply equally well to any other form of autoinhalational apparatus. In the same way other authorities writing on caudal block have stated how important it is that the patient should be fully conversant with the implications of the method which is being employed.

In an institution it is most desirable that both obstetrician and anaesthetist should work together as a team in this matter.

\section{Methods employed during Labour itself}

(a) Drug Therapy

Before describing in detail the various analgesic drugs used it is necessary to consider the requirements of an ideal analgesic, which are :-

(a) It must produce an immediate and satisfactory relief of pain, leaving the mother conscious and co-operative.

(b) It must not depress the foetal respiratory centre, thereby increasing the incidence of asphyxia neonatorum.

(c) It must not inhibit the uterine contractions or it will cause delay in labour and predispose to post-partum haemorrhage. 
(d) The drug must be non-toxic and safe for both the mother and the child.

It has often been stated that there is no ideal single analgesic drug, and although it is possible to conduct the whole labour using only one or one group of non-volatile narcotics, better results are generally obtained by restricting their use to the early Ist stage, and following on with either inhalational or local analgesics. This combination has a synergistic effect and therefore an increased efficiency.

By this means undue depression of the infant's respiratory centres at birth and excessive sleepiness and unco-operation on the part of the mother giving rise to delay in the 2nd stage is more likely to be avoided as the inhalational analgesics are more controllable and more rapidly excreted than the drugs given by other routes.

\section{Simple sedatives}

During the early part of the first stage these are usually all that are required and in this country a mixture which has attained almost universal popularity is one of potassium bromide $20-30 \mathrm{gr}$. and chloral hydrate 15-20 gr. Tincture of opium IO-I 5 minims is frequently added if a more potent effect is required. The mixture should be well diluted with water to prevent nausea and may be repeated in four hours if necessary. To avoid this nausea the mixture may be administered per rectum as described by Marston ${ }^{2}$. The Central Midwives Board allow these drugs to be used by midwives acting alone. This type of sedation enables the patient to sleep between her pains, and frequently tides her over until the commencement of inhalational analgesia at a later period.

\section{The Opium alkaloids}

Morphia, omnopon and heroin have all been used because of their potent analgesic properties, in doses of morphine $\frac{1}{6}-\frac{1}{4}$ grain, omnopon $\frac{1}{3}-\frac{2}{3}$ grain, heroin I' grain. They all possess the same disadvantage in that they cause profound respiratory depression particularly of the foetus and will if used injudiciously increase the rate of asphyxia neonatorum. This foetal depression is maximal about 2 hours after hypodermic injection and therefore they should never be administered within three hours of the expected time of delivery. They are most useful however in the first stage of labour but should not be repeated. The type of case in which they are most strongly indicated is the exhausted patient whose labour is not progressing and for whom a complete rest is essential.

\section{Hyoscine Hydrobromide (Scopolamıne)}

This drug has been used both alone and in combination with morphia, omnopon, nembutak and pethidine. If used alone in doses of $+\frac{1}{5} \mathbb{D}$ grain its main virtue is the production of amnesiac. occasionally however it does produce restlessness $=$ In combination with morphia or omnopon it? enjoyed a considerable vogue for the production of ' Twilight Sleep.' According to Hewer ${ }^{3}$ thi를. method has been abandoned almost entirely in this country because of frequent failure of anal $\stackrel{\mathbb{Q}}{2}$ gesia, prolonged labours, occasional violent excite ment and narcotized babies.

Pethidine (Dolantin, Germany. Demerol, U.S.A. $\overrightarrow{\vec{\omega}}$

This is undoubtedly the most importane addition to the range of non-volatile drugs madeo available in recent years, as it is an excellent. analgesic, has few toxic effects and has no delaying action on labour. It is the hydrochloride of thei ethyl ester of I-methyl-4-phenyl-piperidine-4. carboxylic acid and was first described by Eisleber and Schaumann in $1939^{4}$.

In addition to possessing an analgesic potency midway between morphine and codeine it has an anti-spasmodic action due to depression of the parasympathetic nerve endings similar to atropine ${ }^{\circ}$ This latter property is of value in accelerating the dilatation of the cervix. Toxic effects are slight $\vec{\imath}$ notably vertigo and nausea but some cases of di pes addiction have been reported. From an analysis of 500 cases Barnes $^{5}$ considered that the dringo produces a high degree of analgesia, has little os no amnesic effect, but may contribute to respiratory depression in the foetus in a few cases.

Dosage-The usual initial dose is roo mgm. byø intramuscular injection when labour is well estab $\overrightarrow{0}$ lished, the effect is rapid usually taking place after about 15 minutes. This dose may be repeated ate hourly intervals if necessary but $400 \mathrm{mgm}$. is usually stated to be the maximum required dose it may be administered by mouth but its effect is less certain. More recently it has been shown tha a dose of $150 \mathrm{mgm}$. intramuscularly gives relief. from pain without any respiratory depression ing the infant, but any increase in this dose tends to cause such depression. Pethidine is excellent? when used before an inhalational technique withp which it can be conveniently combined.

\section{The Barbiturates}

Almost all the derivatives of barbituric acip have been tried in labour but in this country theyew have never achieved any universal popularity as they do not in any way fulfil the requirements of the ideal analgesic already described. Nembuta市 is the most commonly used the initial dose being 3 gr. by mouth with additional doses of $1 \frac{1}{2}$ gr. every 3-4 hours to a maximum of $7 \frac{1}{2}-9$ gr. in $12 \frac{\mathrm{D}}{\mathrm{D}}$ hours. It has been combined both with chlora昂 
hydrate $20 \mathrm{gr}$. and with scopolamine $T \frac{\mathrm{l}}{5 \pi} \mathrm{gr}$. but has the disadvantage of producing respiratory depression and occasionally restlessness without any high degree of analgesia or amnesia. Pentothal sodium and pentothal acid have also been used in a similar manner by mouth.

\section{Drugs given by the rectal route}

The technique of the administration of drugs by this route is the same in principle for them all. For the best results to be obtained the lower bowel should be emptied by an enema given at the onset of labour, or failing this the cleansing enema must be given at least one hour before the drug itself is administered. To introduce the drug a rubber catheter is inserted into the rectum between pains, and the tip of it guided above the presenting part by means of a finger inside the rectum. The fluid itself should be introduced in a pain free interval and if a pain occurs during the injection the buttocks are compressed together until it is over.

\section{(a) Paraldehyde}

The main advantages of this drug are its stability and the fact that in therapeutic doses there is no clinical depression of the respiratory centre. The analgesia obtained is poor when compared with the true analgesic drugs, and nowadays its most frequent use is to obtain a refreshing sleep in a woman undergoing a tedious labour such as may be expected in an elderly primipara. It can be used with complete safety to both mother and child and although the infant may be somewhat drowsy respiration commences without delay. The dose is from $\frac{1}{2}-1$ drachm per stone of body weight to a maximum of 8 drachms and is made up to form a ro per cent. solution with normal saline.

\section{Ether-in-oil}

This method is used very much more extensively in America than in this country but has been favourably reported on by Milne and Younger ${ }^{6}$. It developed as a modification of the work of J. T. Gwathmy who used ether by the rectum for the production of anaesthesia. The advantages claimed for it are its complete safety, almost universal application and ease of control by the practitioner working single-handed. In many parts of America it takes the place of gas and air in this country.

The technique of administration as described by Lull and Hingson ${ }^{7}$ is as follows :-

A cleansing enema of ro per cent. sodium bicarbonate is given as mentioned previously. As soon as the patient's pains become uncomfortable she is given nembutal $3-4 \frac{1}{2}$ gr. by mouth; when the effect of this is wearing off it may be repeated or in the case of a protracted labour morphine gr. $\frac{1}{6}-\frac{1}{4}$ may be substituted. The ether enema, which may be either of the following :-

(a) Ether $2 \frac{1}{2}$ oz. olive oil $1 \frac{1}{2}$ oz. or

(b) Ether $2 \frac{1}{2}$ oz. paraldehyde 2 drachms, olive oil 9s. $4 \mathrm{oz}$.

is given when once again the pains become uncomfortable.

The analgesic effect is maximal after about 40 minutes and lasts from 2-6 hours; the ether may be repeated as required, the average nullipara requiring 2-3 instillations, the average multipara $1-2$. In case of need during the crowning of the head the analgesia may be augmented by some form of inhalational anaesthetic.

\section{Bromethol (Avertin)}

This drug is occasionally used in the same way as described for paraldehyde, it has however the added disadvantages of causing respiratory depression and is reported to depress the uterine contractions. The dose is $75 \mathrm{mgm}$. per kilo of body weight less 6 kilos for the weight of the uterus and its contents. Under no circumstances must this dosage be increased, if the degree of analgesia produced is insufficient gas and air or gas and oxygen by inhalation should be superimposed.

\section{(b) The Inhalational Analgesics}

The importance of antenatal instruction in the use of any type of apparatus for this method has already been stressed and it must be ensured that the patient is conversant with the following points :-

(I) She must learn how to apply the face-piece to obtain an air-tight fit.

(2) The object of the finger-hole safety device if present must be understood and how it is occluded.

(3) For analgesia to be effective inhalation must be commenced immediately she feels that a pain is imminent. This enables her to hold her breath and bear down during the second stage whilst the pain is at its height.

\section{Nitrous oxide}

Nitrous oxide possesses many advantages for analgesia in obstetrics. It will produce a rapid and satisfactory analgesia, will not interfere with uterine contractions and in the absence of anoxia is completely non-toxic to both mother and child. It is however a weak anaesthetic and for an adequate effect to be obtained the oxygen intake of the patient when using any machine is reduced to a level bordering on the physiological minimum. Therefore as a method it is contra-indicated in a patient who cannot tolerate a reduced oxygen blood tension because of the effect of anoxia on a 
pre iously damaged myocardium. There is complete absence of any foetal depression, and labour is frequently hastened. Because it does not interfere in any way with liver function it is the method of choice in the toxaemias of pregnancy.

\section{Nitrous oxide and oxyg:n}

This is probably the best method available and a mixture of from 10-15 per cent. oxygen and 90-85 per cent. nitrous oxide is the one usually employed by an anaesthetist supervising the analgesia and using an intermittent flow machine. Three to four breaths at the onset of a pain are required before analgesia is established. The patient can control her own analgesia in this way until the late second stage, when if necessary the anaesthetist can take over the machine and produce a full anaesthesia.

Special types of apparatus have been designed for the production of an intermittent flow, this is essential to avoid wastage of expensive material. The McKesson and Portanest machines are the most popular but recently Chassar Moir has reported favourably on a machine which has been used in Denmark for some years.

\section{Nitrous oxide and air}

In an attempt to reproduce the satisfactory conditions obtainable with gas and oxygen, without constant supervision being necessary Minnitt introduced his gas and air machine in $1933^{1}$. At present this is the only method available for use by the domiciliary midwife. The original machine was constructed to deliver approximately 45 per cent. of nitrous oxide and 55 per cent. of air. Although in a few cases there is failure to obtain perfect analgesia many thousands of patients have obtained satisfactory relief without ill effect to either mother or child. It is well recognized that most of the failures occur in the hysterical, uncooperative type of patient. The principle governing the design of this machine was to produce an apparatus which would be completely safe for the patient and yet would require the minimum amount of supervision. To attain these ends it was necessary to sacrifice a certain amount of efficiency.

When a constant gas-air mixture is all that is available it is difficult to obtain analgesia with sufficient rapidity from the moment when the patient feels that a pain is imminent to the time when the pain is at its height. The experienced midwife overcomes this difficulty by anticipating the onset of a pain, but this entails constant and alert supervision. To accelerate the onset of analgesia other workers have attacked the problem from a different angle. Moir $^{8}$ has designed a machine in which a limited quantity of pure nitrous oxide ( $\frac{5}{8}$ gallon) flows into a reservoir bag from which the patient breathes, as soon as this has become empty only air is available. The. apparatus is so designed that the bag takes one $\vec{F}$ minute to refill and no more nitrous oxide can be obtained in this period. In the Wellhouse? apparatus designed by Elam ${ }^{9}$ this principle has $\frac{\bar{c}}{\bar{s}}$ been developed so that following one breath of $\frac{\sqrt{\sigma}}{\bar{\sigma}}$ pure nitrous oxide the ordinary mixture of gas $\cong$ and air is available. This was thought to be necessary as the period of analgesia produced by the $\vec{\circ}$ Moir apparatus is frequently insufficient to cover the whole pain. An attachment is now available $\vec{\omega}$ which can be fitted to the Minnitt's apparatus to? produce the same sequence of events.

\section{Trichlorethylene (Trilene)}

Trichlorethylene is an unsaturated chlorinated hydrocarbon, which is a colourless transparent. fluid with a sweet odour. Both the liquid and its vapour are stable and non-inflammable and for ${ }_{0}$ this reason it can be safely used in domiciliary practice. The vapour is non-irritant to the res- $\overrightarrow{0}$ piratory tract at low concentrations, is rapidly absorbed through the lungs and has a powerfulo narcotic action but it is somewhat slowly excreted. $\stackrel{\text { }}{-}$ The drug is relatively non-toxic to the healtioy $\overrightarrow{0}$ liver and kidneys and has very little effect $\$$ the blood chemistry and for this reason it has been used without ill effect in the toxaemias of pregto nancy. Trichlorethylene is produced under the trade name of Trilene which is coloured blue to distinguish it from chloroform. Because of its low $\frac{0}{\circ}$ volatility the use of an open mask is unsatisfactory, $\cong$ and an apparatus for the administration of a Trichlorethylene vapour/air mixture was first 3 described by Freedman ${ }^{10}$. This is designed for self-administration in a manner similar to the Minnitt's machine and is claimed to produce a윽 constant vapour strength. The finger hole safety device is incorporated as in the gas and air 3 machines in order that analgesia alone and not anaesthesia will be obtained.

A modified version of the original Freedman's machine is now being used with increasing frequency both in hospitals and domiciliary $\frac{D}{0}$ practice. Very satisfactory results as regards relief of pain are obtained and in this respect it appears $\stackrel{\sim}{\circ}$ slightly superior to gas and air. Clinically there $N$ are no toxic effects beyond the occurrence of $N$ occasional cardiac arrythmias and it does not ${ }^{\omega}$ appear to influence the course of labour. The only serious drawback to the method is the tendency of a very few patients to pass beyond the stage of $\cong$ analgesia into one of unco-operative stupor. When this is observed the withdrawal of the ${ }^{\circ}$ inhaler rectifies the condition and there seem to be $\overrightarrow{\mathbb{D}}$ no ill effects, but for complete safety constant 
supervision of the patient is essential. Trichlorethylene has been used frequently without ill effects on cases of cardiac insufficiency.

This method is most satisfactorily combined with pethidine given in the early stages of labour, the only combination of drugs which must be avoided is that a cyclopropane anaesthetic in a closed circuit system must not be superimposed on a trichlorethylene analgesia, owing to the danger of toxic effects, due to decomposition in the soda-lime.

Several different types of apparatus have been constructed with which analgesia may easily and speedily be deepened into anaesthesia if required in the second stage, of these the best known are those of Marrett ${ }^{11}$ and Hyatt ${ }^{12}$. Recently an extremely portable apparatus for the production of analgesia alone has been described by HaywardButt ${ }^{13}$.

Trichlorethylene is a suitable alternative to gas and air. For domiciliary practice the apparatus has the advantage of being more easily portable and also the cost per case is very small.

\section{Chloroform}

It is now just over Ioo years since Simpson first used chloroform in obstetric practice and it still remains one of the most commonly used analgesics in domiciliary practice at the present time. The reasons why it has retained its popularity for such an immense period of time are the rapid and efficient analgesia produced, the simplicity of its administration, without any complicated equipment, and the fact that it is both non-inflammable and economical to use. It will be noted that these same advantages can be claimed for trichlorethylene.

Chloroform however is by no means without its disadvantages, it depresses contraction of the uterine musculature and therefore tends to prolong labour and predispose to post partum haemorrhage. It is toxic to both mother and child and although it is sometimes claimed that the pregnant mother is immune to the risk of primary cardiac failure, that she is not immune to all the dangers of chloroform was well shown in the Investigation undertaken by the Royal College of Obstetricians and Gynaecologists in 1934 when there were two deaths attributable to this drug. Chloroform has been the subject of much bitter controversy. It is probable that its opponents have over emphasized its dangers, it is equally certain that its adherents have minimized them. Since there are now so many undoubtedly safer drugs available it is hard to produce a convincing argument for the retention of this drug.

Chloroform may be administered intermittently on an open mask using a drop bottle or chloroform capsules. Various inhalers may be used instead, probably the safest of which is Mennell's modification of Junker's bottle.

In view of the fact that trichlorethylene possesses all the virtues of chloroform without its disastrous drawbacks it is tending to replace chloroform in domiciliary practice among many practitioners.

\section{Other inhalational methods}

The irritant properties of ether vapour preclude its use to any great extent for intermittent analgesia, but when the requisite closed-circuit equipment is available 5 per cent. cyclopropane in oxygen may be used and in this concentration it has little or no depressant effect on the foetus. This has the advantage that the mother is breathing an excess of oxygen and is probably the method of choice in a patient whose cardiac insufficiency is giving rise to anxiety. Cyclopropane may also be used to advantage in toxaemias.

\section{(c) Local and Regional Techniques}

The main attraction of any of the following methods is the complete absence of any toxic effects on the child from the analgesic used; the main drawback is the specialized knowledge and skill required for their administration and the fact that few are suitable for use outside an institution.

\section{(1) Subarachnoid block}

This has no place in a straightforward labour. Under certain circumstances however a low spinal block to Sacral I may be used for a low forceps delivery. In these cases it must never be used if the mother is suffering from shock or if the head is not on the perineum.

\section{(2) Caudal block (Extra-dural block)}

The dural sac terminates in the sacral canal at the level of the lower border of the second sacral vertebra. Any fluid injected through the sacral hiatus into the sacral canal will spread upwards extra-durally and come into contact with the spinal nerves where they pass out from the meninges. The level to which this fluid will rise depends almost entirely on the volume of fluid which is injected. The level of analgesia therefore which is to be obtained when a local analgesic solution is injected.through the sacral hiatus can be accurately determined.

It has been shown that the sensory nerve pathways from the body of the uterus enter the spinal cord through the IIth and I2th dorsal segments. Sensory nerve pathways from the lower birth canal enter the cord via the sacral segments. Motor nerves to the uterus on the other hand come from the upper thoracic segments; if the nerve pathways below the roth dorsal segment are 
blocked, the pain of labour is entirely abolished without interfering with the uterine contractions. It is on these anatomical facts that the success of this method depends.

The disadvantage of caudal block is in the limitations imposed upon its use. Because of the rigid asepsis required it can only be employed safely in an hospitalized patient, and she must be in the labour theatre at least one hour before delivery is due. For the complete success of the method the possibility of its use should have been envisaged before the onset of labour so that the mother is fully conversant with the principle, and only a co-operative and temperamentally suitable patient should be chosen. It is said by some that 20 per cent. of patients have sacral abnormalities which physically preclude the method and further the technique can be made extremely difficult by obesity. Local infection at the site of injection is a complete contraindication and it must only be used with circumspection in cases of profound anaemia and dehydration. Caudal block is also contra-indicated in certain obstetric conditions, placenta praevia, premature separation of the placenta and disproportion. One further precaution must be observed namely a history of sensitivity to the analgesic agent.

This method of analgesia has achieved a much greater popularity in the U.S.A. than in this country. Originally a single dose method was used but as the period of analgesia was often insufficient continuous techniques have been introduced in which a needle is left in position in the caudal canal. As the needle was liable to breakage from movement of the patient Lull and Hingson describe the use of a malleable needle or the introduction of a ureteric catheter through a large bore needle which is then withdrawn leaving the catheter in position. The drug advocated is I $\frac{1}{2}$ per cent. metycaine, using an initial dose of 30 cc. Maintenance doses depending on the rate of metabolism of the drug by the patient are of $20 \mathrm{cc}$. every half to one hour. The indication for a repeat dose is given by a dropping of the level of the skin analgesia. A continuous drip technique has also been described.

Great care must be taken when using any of these techniques to avoid either intrathecal or intravenous injection of the drug, as an added precaution when aspiration tests prove negative, 5 cc. of the initial injection should be given and a pause of 5 minutes made before injecting the remainder. In this way intrathecal injection will be shown by loss of movement in the toes.

\section{Local Infiltration}

The injection of a local analgesic into the vulva is frequently used for an episiotomy or for the repair of perineal lacerations after birth. In an emergency some relief may be obtained during a normal delivery to ease the passage of the head through the perineum by infiltrating with I per cent. procaine around the vaginal orifice and between the vaginal wall and the rectum. Injections should also be made into the levator ani muscles and into the ischio-rectal fossae on either side, from a point midway between the anus and the tuberosity of each ischium to a depth of two inches.

\section{Intravenous Procaine}

A continuous infusion of intravenous procaine has been used recently in the U.S.A. to produce obstetrical analgesia. This method although only suitable for hospital use possesses the advantage of simplicity when compared with caudal analgesia. The concentration of procaine used in the infusion is usually r.o per cent. made up in an aqueous 5 per cent glucose solution. The only apparent danger is the threat of convulsions from overdose which is avoided by pre-medication with a barbiturate usually nembutal $\mathrm{I} \frac{1}{2}$ to 3 gr. by mouth prior to commencing the infusion and by the anaesthetist constantly watching the patient for any twitching of the facial or other muscles in which case the drip is immediately stopped ${ }^{14}$. As however this method is still in an experimental stage its value cannot yet be assessed.

Whatever method of analgesia is to be employed it is of paramount importance to bear in mind the effect of the analgesic agent on the foetus, as any method of pain relief however effective which markedly raises the incidence of asphyxia neonatorum is unsuitable for general use. As the nonvolatile narcotics have a more prolonged depressant action in this respect than the volatile inhalational agents particularly trichlorethylene and gas and air, in most cases the best results are obtained by using the former drugs for the earlier stages of labour and reserving the inhalational agents for the latter part of the first stage and second stage.

\section{REFERENGES}

I. MINNITT, R. J. (1944), 'Gas and Air Analgesia.' 2nd Edition, London. Bailliêre, Tindall and Cox.

2. MARSTON, A. D. (1946), The Practitioner, 157, 373.

3. HEWER, C. L. (1944), 'Recent Advances in Anaesthesia and Analgesia,' 5th Edition, 292. Churchill, London.

4. EISLEB, O., and SCHAUMANN, O. (1939), Dtsch. Med. Wsch, 65, 967.

5. BARNES, J.'(1947), Brit. Med. Fournal, i, 437-442.

6. MILNE, M. I., and YOUNGER, E. R. (1947), Brit. Med. Fournal, ii, i6.

7. LULL, C. B., and HINGSON, R. A. (1945), 'Control of Pain in Childbirth,' and Edition. Heinemann, London.

8. MOIR, C. (1937), Lancet, i, 615.

9. ELAM, J. (1939), Fournal of Obst. and Gyn. Brit. Emp., 46, No. $1,6 \mathrm{r}$.

10. FREEDMAN, A (1943), Lancet, ii 696

I I. MARRETT, H. R. (1942), Brit. Med. Fournal, i, 643.

12. HYATT, A. L. (1947), Brit. Med. Fournal, ii, 27.

13. HAYWARD-BUTT, J. T. (1947), Lancet, ii, 865.

14. JOHNSON, K., and GILBERT, C. R. A.' (1946), Curr. Res. in Anaesth. and Analg., 25, No. 4, 133-146. 